\title{
Alimentación Saludable para Personas de Edad: Nuevas Ensaladas ${ }^{1}$
} IFAS EXTENSION

\section{Jennifer Hillan ${ }^{2}$}

Las ensaladas son unos platos fáciles y rápidos con infinitas posibilidades. Cuando éstas se combinan con pan o galletas integrales constituyen unas comidas saludables y convenientes. ¡Pruebe alguna de las ideas que le sugerimos en su próxima ensalada!

Elija variedades de lechugas que tengan color, como por ejemplo la lechuga roja o la variedad romana. Las variedades con más color contienen una mayor cantidad de nutrientes.

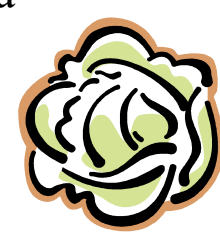

Añada rodajas de tomate a la lechuga.

Termínelo con requesón descremado.

Pruebe a mezclar vegetales y frutas para una mayor variedad. Rodajas de manzanas o de mandarina se pueden combinar con hojas de espinaca.

Rellene las mitades de peras o melocotones con requesón descremado. Ponga encima frutos secos.

Añada frijoles en lata a sus ensaladas. Experimente con garbanzos, habichuelas verdes o

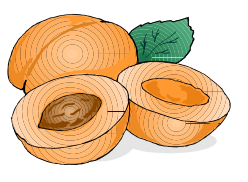
frijoles rojos.

Haga ensaladas con vegetales en lata. Mezcle vegetales como la zanahoria, la remolacha o las habichuelas verdes.
Añada proteína a su ensalada con trozos de queso, trozos de huevos cocidos o latas de carne o pescado

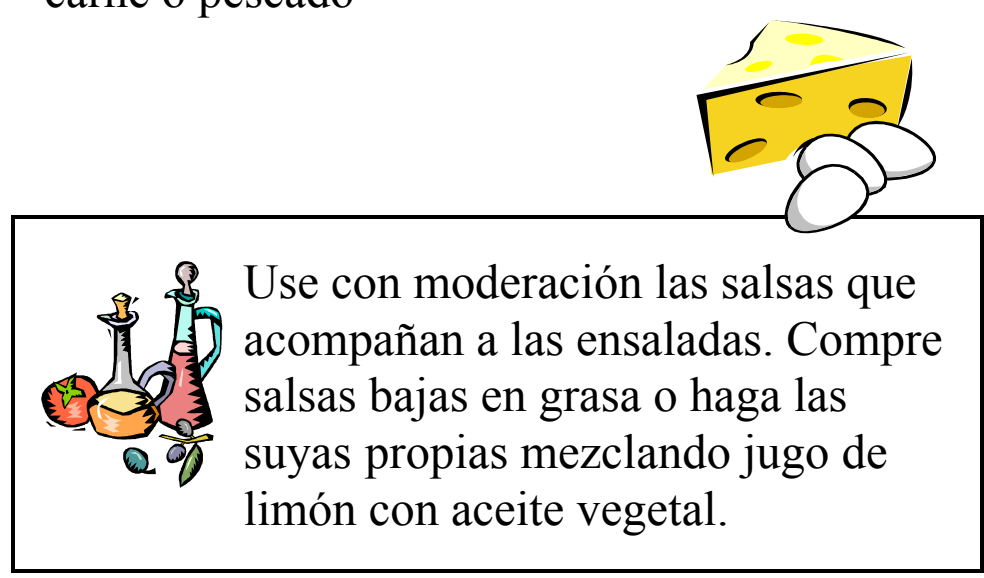

\section{Consejos}

No lave los ingredientes hasta que esté listo para consumirlos; se mantendrán frescos por más tiempo.

Congele los restos de cebollas, pimientos y champiñones para usarlos en el futuro.

Si es posible, compre con un amigo y comparta las frutas y las verduras que son demasiado grandes para ser consumidas por una sola persona.

1. This is document FCS 8696-SPAN, one in a series of the Department of Family, Youth and Community Sciences, Florida Cooperative Extension Service, Institute of Food and Agricultural Sciences, University of Florida, Gainesville, FL 32611. Publication date: February 2005. The English version of this Spanish language leaflet is Healthy Eating for Elders:

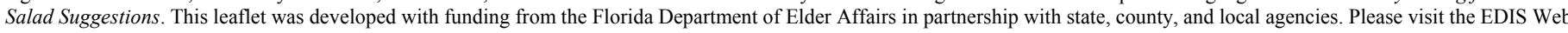
site at http://edis.ifas.ufl.edu.

2. Jennifer Hillan, MSH, RD, LD/N, former ENAFS nutrition educator/trainer, Department of Family, Youth, and Community Sciences, Institute of Food and Agricultural Sciences, University of Florida, Gainesville, FL 32611. English version reviewed by Linda B. Bobroff, PhD, RD, LD/N, professor, and Leigh Ann Martin, MESS, former ENAFS project coordinator, University of Florida. Translated by Sergio Romero, MS, ATC, University of Florida. Translation reviewed by Isabel Valentín-Oquendo, MS, RD, former curriculum coordinator FNP, University of Florida. 